\title{
Arms pact could boost US-Russian science
}

Nuclear scientists in Russia and the United States say that the sputtering relationship between their weapons laboratories could be rekindled by an agreement to cut the nations' nuclearweapons arsenals.

US President Barack Obama and Russian President Dmitry Medvedev announced on 6 July that they intended to reduce their stockpile of warheads. The pair also discussed scientific collaboration as a way to strengthen ties between the two nations.

Even during the cold war, US and Soviet scientists worked together on specific issues, such as the development of fusion energy. Wider programmes began in earnest after the fall of the Soviet Union, when the US government stepped in with millions of dollars in

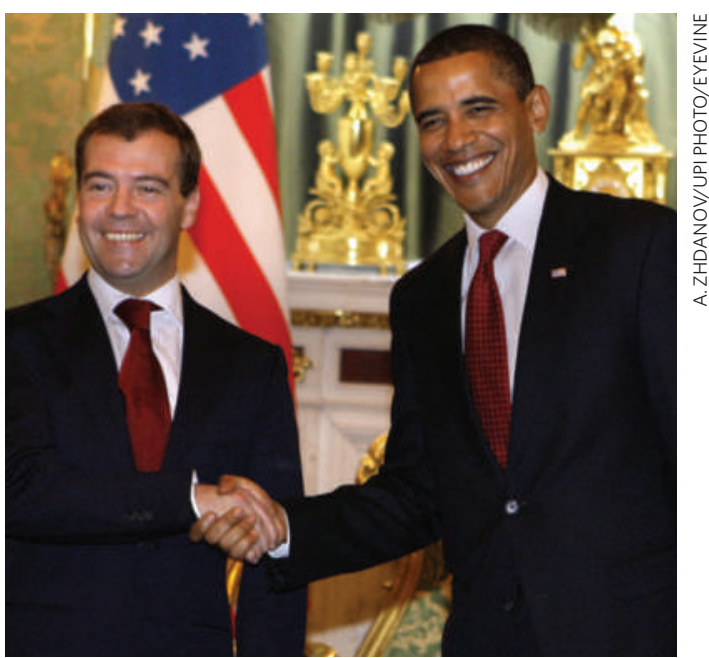

Presidents Dmitry Medvedev and Barack Obama want to cut back their nations' nuclear-weapons stockpiles.

\section{funding for scientific collaborations.}

That cooperation remained strong until the new millennium, but "has dropped off sharply during the past eight years or so", says Siegfried Hecker, a metallurgist at Stanford University in California, and former director of the Los Alamos National Laboratory in New Mexico, one of the two main US nuclear-weapons labs.

In 2000, Vladimir Putin, Russia's newly elected president, began tightening up security and scaling back access to the nation's military laboratories. Meanwhile, politicians in the United States were growing increasingly sceptical of programmes that directed tax dollars into the Russian defence establishment, says David Holloway, a political scientist at Stanford University who has studied the Soviet weapons complex.

Programmes to improve the physical security and accounting of nuclear materials have survived the cooling political climate, but Hecker says that "most of the lab-to-lab scientific exchanges are gone".

Obama's promise to "reset" the US-Russian relationship has sparked hopes that these exchanges can be renewed. In March, Hecker met with other US and Russian scientists in Moscow to discuss how to renew strategic and scientific cooperation.

The collaboration is likely to be more even-handed than it was in the 1990s because conditions at Russian laboratories have improved so dramatically, according to Adriaan van der Meer, the executive director of the International Science and Technology Center in Moscow, which was set up in 1992 to foster collaboration between the former Soviet states and the West.

"We need to move to a true partnership," agrees Hecker. Among the various projects Hecker would like to see supported are efforts to develop 'safer' warheads that are more resistant to tampering and accidental detonation, improved detectors for combating nuclear smuggling and databases for tracing the origin of bomb material. There is also great potential for cooperation on civilian nuclearpower research, he says. "We have superb modelling and the Russians have excellent experimental facilities."

Holloway, who attended the March meeting in Moscow, says that scientists from both countries are clearly eager to embark on a new cooperative relationship. But he notes that much more diplomatic work must be done before researchers can start purchasing plane tickets.

Russia is currently unhappy with US intentions to place a missile defence system in Europe, for example, while the United States has halted a plan for civilian nuclear cooperation after Russian forces invaded the Republic of Georgia last year. Until the two sides begin to tackle these larger issues, says Holloway, scientific collaboration may be slow to blossom. Geoff Brumfiel 